\title{
Optimierte Filtertechnik für Abwasser und Prozessbäder
}

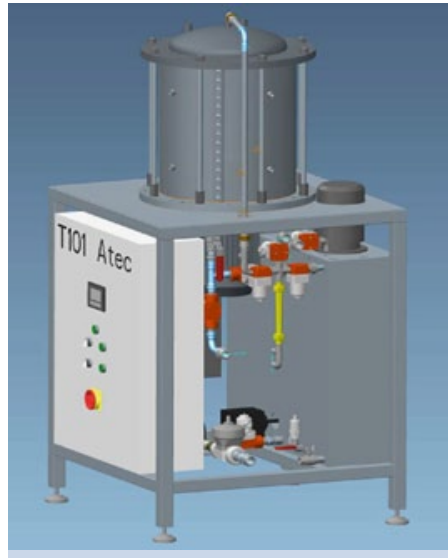

Kompaktfilter für die Behandlung von Prozessbädern mit kleineren bis mittleren Volumina

\section{Kompaktfilter für kleinere bis} mittelgroße Prozessbäder

Als Neuentwicklung von Atec steht ein Kompaktfilter zur Verfügung, der optimal abgestimmt ist auf die Pflege von kleinen bis mittleren Prozessbädern wie zum Beispiel Spül- und Entfettungsbädern.

Durch die Integration aller nötigen Behälter und Aggregate, kann die Anlage ohne größere Umbaumaßnahmen im Bypass an das aufzubereitende Bad angeschlossen werden. Ein energiesparendes Rührwerk im Inneren des Filterrohres erzeugt eine extrem hohe Überströmung der Membrane, so dass die Anlage mit einem geringen Druck zwischen 0,8 und 1,5 bar betrieben werden kann. Die Flachmembranen können in Vorversuchen optimal an das Prozessmedium angepasst werden. Die Anlagen sind komplett automatisiert und mit einer modernen Siemens-SPS ausgestattet.
Cross-flow-Filtration für große bis sehr große Volumen

Für große bis sehr große Volumen, sowohl im Prozess, aber auch im Abwasser, bietet sich die Cross-flow-Filtration mit Standardfiltermodulen an, die je nach Membrantyp mit bis zu 480 Quadratmeter Filterfläche realisiert werden können und dennoch eine kleine Standfläche von 1,8 x 3,5 Metern aufweisen.

Das Herzstück der Filteranlage bilden die um ein Zentralrohr positionierten Membranmodule sowie ein energiesparendes Rührwerk. Dieses erzeugt eine sehr starke Überströmung an der Membranoberfläche, die für die Filtrationsleistung und die Aufkonzentration von entscheidender Bedeutung ist. I

\section{Kontakt:}

Atec Automatisierungstechnik GmbH

Tel.0731/977 59-0, info@atec-nu.de,www.atec-nu.de

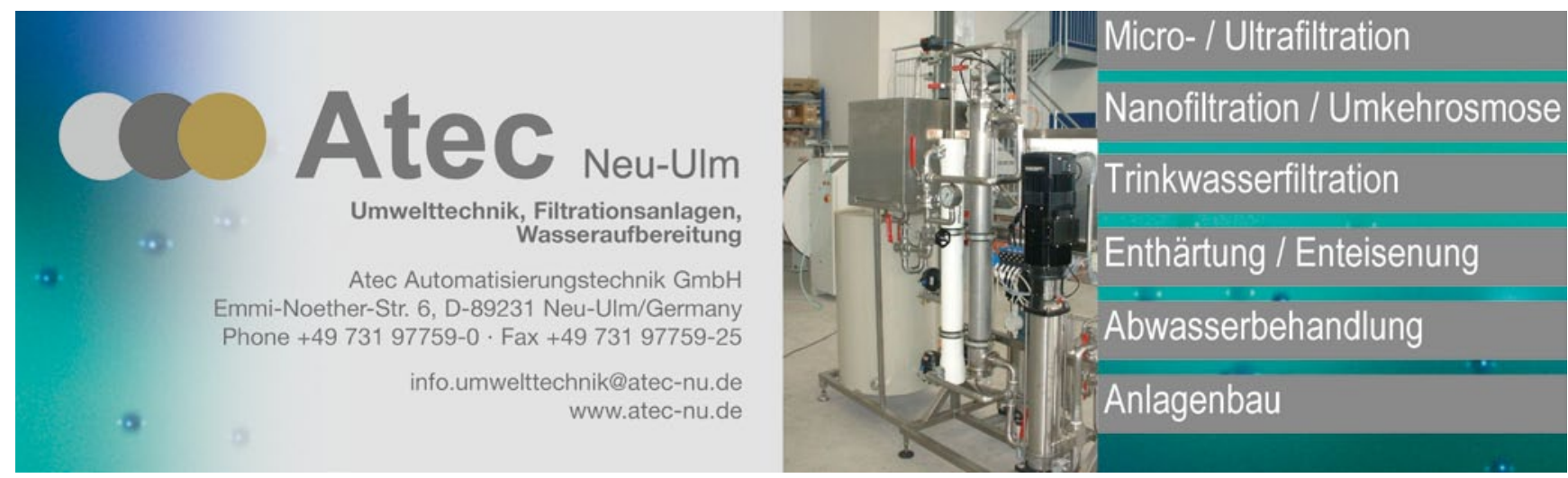

